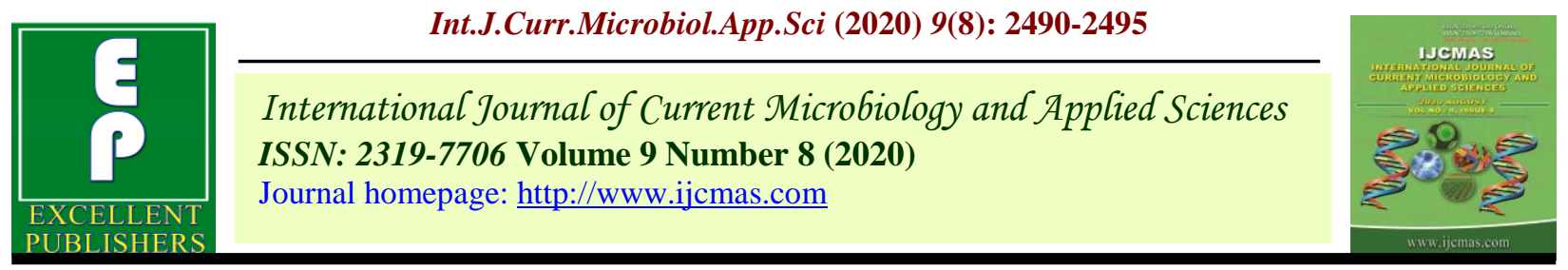

Original Research Article

https://doi.org/10.20546/ijcmas.2020.908.284

\title{
Estimated Yield Forecasting of Rice and Wheat for Central Uttar Pradesh using Statistical Modal
}

\author{
Naushad Khan, Ajay Kumar*, Vijay Dubey, C.B. Singh, \\ Sanjeev Kumar and Shubham Singh
}

Department of Agronomy, Chandra Shekhar Azad University of Agriculture \& Technology, Kanpur Uttar Pradesh, India

*Corresponding author

\section{A B S T R A C T}

Keywords

Rice, Yield

forecast, Central

Uttar Pradesh,

Weather data and SMW

Article Info

Accepted:

22 July 2020

Available Online:

10 August 2020
Twenty three years (1992-2015) weather data of rainfall (mm), Maximum and Minimum temperature $\left({ }^{\circ} \mathrm{C}\right)$, maximum and minimum relative humidity $(\%)$ and yield data of rice and wheat crop for 12 districts were used for yield prediction using statistical method under FASAL Project, Department of Agronomy, Chandra Shekhar Azad University of Agriculture \& Technology, Kanpur Uttar Pradesh. The regression equation was generated for statistical method using SPSS package. The models were validated using 2 year (2016 and 2017) data. The result indicated that model explained 45 to 73 percent variation in rice crop yield and 49 to 74 percent variation in wheat crop in different districts. The $F$ value 13.53 (Mathura) to 57.20 (Auraiya) variation for rice crop and 11.42 (Agra) to 54.51 (Mainpuri) variation for wheat crop was observed in different districts. The percent standard error was between 90.67 (Farrukhabad) to 217.73 (Auraiya) for rice crop and 153 (Mathura) to 252 (Kanpur Dehat) for wheat crop. This revealed that the models can be used to some extent for yield prediction in different districts of Central Uttar Pradesh.

\section{Introduction}

Crop acreage estimation and crop yield forecasting are two components, which are crucial for proper planning and policy making in the agriculture sector of the country. Estimation of crop yield in regional level is the basis for planning of crop production prospects at national level. Models based on weather parameters can provide reliable forecast of crop yield in advance of harvest and also forewarning of pests and diseases attack, so that suitable plant protection measures could be taken up timely to protect the crops (Agrawal and Mehta, 2007). Agrometeorology and Land based observations (FASAL) is an important project operational at Ministry of Agriculture, Government of India in collaboration with Space Application Centre (SAC), Institute of 
Economic Growth (IEG) and India Meteorological Department (IMD). Under this FASAL project, IMD in collaboration with 46 Agromet Field Units (AM FU) located at different parts of the country develops intra-seasonal operational yield forecast at district and state level for 13 major crops of India during Kharif and Rabi seasons using statistical model (Ghosh et al., 2014).

Rice and wheat are the major food grain crops of Central Uttar Pradesh. The Central Uttar Pradesh shares about 36\% acreage and 35\% production of rice. $43 \%$ acreage and $44 \%$ production of wheat in twelve districts of Uttar Pradesh viz. Agra, Auraiya, Etawah, Etah Farrukhabad, Hardoi, Kannauj, Kanpur dehat, Kanpur Nagar, Mainpuri, Mathura and Unnao falling under jurisdiction of the AMFU, Kanpur under Chandra Shekhar Azad University of Agriculture \& Technology, Kanpur which shares about $32 \%$ of rice acreage and $30 \%$ of rice production, $41 \%$ of wheat acreage and $42 \%$ of wheat production in Central Uttar Pradesh (Anonymous, 2010). The present study was undertaken to investigate the feasibility of estimating the productivity of rice and wheat crops based on weather variables using past weather and yield records of different districts of Central Uttar Pradesh.

\section{Materials and Methods}

Crop yield data of Rice and wheat for the period of recent 23 years (1992-2015) were used to develop yield forecasting models. The weather data was used in standard meteorological weeks (SMW) wise starting from $27^{\text {th }}$ to $38^{\text {th }}$ SMW of each year i.e. the period from transplanting to harvest of rice and from $40^{\text {th }} \mathrm{SMW}$ of current year to $11^{\text {th }}$ SMW of next year from sowing to harvesting of wheat. The variables used in this study were weekly rainfall $(\mathrm{mm})$, maximum and minimum temperature $\left({ }^{\circ} \mathrm{C}\right)$, $\mathrm{RH}-\mathrm{I}$ i.e. morning relative humidity (\%) and RH- II i.e. afternoon relative humidity (\%) for rice crop. All the weather parameters together with solar radiation data were used for wheat yield prediction. Rainfall was not used as a parameter for wheat forecasting. For selecting the best regression equation among number of independent variables, stepwise regression procedure was adopted. Statistical Package for Social Science (SPSS) computer software was used for the analysis of data with probability level of 0.05 to enter and 0.1 to remove the variables. A regression model was fitted considering the entered variables obtained from individual stepwise regression analysis to predict the yield of rice and wheat for subsequent years. The multiple linear stepwise regression analysis has been developed on the basis of examination of coefficients of determination (R2), Standard Error (SE0 of estimates values resulted from different weather variables. The $\mathrm{F}$ values are used for the degree of accuracy of each considered correlation to fit the measured data. $F$ value provides information on the long term performance of the models. The best agro meteorological indices were selected to develop agro meteorological yield model for the each district as per methodology given by Ghosh et al., (2014). Yield forecast models for all twenty three districts which produce rice and wheat have been developed and their performance $\mathrm{s}$ have been validated against the observed year in 2015-16 and 2016-17.

\section{Results and Discussion}

\section{Rice yield forecast}

The yield variations explained by model together with standard error are shown in Table 1. Coefficient determination (R2) has been significant at 5\% probability level for rice in all the twelve districts of Central Plain Zone of Uttar Pradesh. The R2 was ranged between $45 \%$ (Hardoi) to 73\% (Farrukhabad). 
The percent $\mathrm{F}$ value was ranged between 13.53 (Mathura) and 57.20 (Auraiya), However, the percent standard error was ranged between 90.67 (Farrukhabad) and 217.73 (Auraiya). The best agro meteorological indices to incorporate in the agro meteorological yield model for rice was selected as, RH-I (Z41) for Agra district, TIME for Auraya, Etawah, Farrukhabad, Kanpur Dehat, Mainpuri district, TIME, RH-1 (Z41) for Etah, Tmax. $x$ Tmin (Z121) for Hardoi, Kannauj district, TIME, Rain (Z31) for Kanpur district, Rain (Z31) for Mathura district and TIME x RH I (Z141) for Unnao district.

The validation of model for rice during the year 2016 and 2017 are shown in Table 2. Result revealed that in 2016, the models for Agra (10.15\%), Auraya (-5.26\%), Etawah $(-5.15 \%), \quad$ Etah $(18.40 \%), \quad$ Farrukhabad (7.24\%), Hardoi (11.02\%), Kannauj $(10.70 \%)$, Mainpuri (-1.68\%) and Unnao $(-16.70 \%)$ districts have underestimated the yield while over estimation was observed in Kanpur Dehat (5.72\%), Kanpur (6.30\%), and
Mathura (1.56\%) in 2016. Whereas, during 2017 Rice yield under estimated in all the twelfth districts, models Auraya (-2.44\%), Etah (21.93\%), Hardoi (21.78\%), Kannauj (19.80\%), Mathura (28.23\%) and Unnao $(-2.70 \%)$ and over estimated in Agra (9.54\%), Etawah (2.21\%), Farrukhabad (8.69\%), Kanpur Dehat $(8.37 \%)$, Kanpur $(5.40 \%)$ and Mainpuri (2.57\%) districts. Models had less than $\pm 10 \%$ error in rice yield prediction for all districts during both the years. This has indicated that the model can be used for prediction of rice yield in above districts. The result revealed that agrometeorological yield model explained the yield variability due to variations in temperatures, rainfall and relative humidity during the different stages (tillering, panicle initiation, booting and physiological maturity). Maximum and minimum temperatures were found common agrometeorological indices for most of the districts of this region. However, rainfall with relative humidity is also proved important agrometeorological indices for some of the districts of Central Uttar Pradesh.

Table.1 Yield forecast models of rice for different districts of Central Uttar Pradesh

\begin{tabular}{|c|c|c|c|c|c|c|c|c|}
\hline \multirow[t]{2}{*}{ SN } & \multirow[t]{2}{*}{ District } & \multirow[t]{2}{*}{ Equation } & \multirow[t]{2}{*}{$\mathbf{R}^{2}$} & \multirow{2}{*}{$\begin{array}{c}\text { Forecast } \\
\text { yield } \\
\text { (Kg/ha) }\end{array}$} & \multirow[t]{2}{*}{$\mathbf{F}$} & \multirow{2}{*}{$\begin{array}{c}\text { Std } \\
\text { Error }\end{array}$} & \multicolumn{2}{|c|}{ ERROR (\%) } \\
\hline & & & & & & & 2016 & 2017 \\
\hline 1 & AGRA & $\mathrm{Y}=601+30.50 * \mathrm{Z} 41$ & 0.59 & 2367 & 32.71 & 146.52 & 10.15 & 9.54 \\
\hline 2 & AURAIYA & $\mathrm{Y}=1927+45.67 *$ TIME & 0.71 & 3206 & 57.20 & 217.73 & -5.26 & -2.44 \\
\hline 3 & ETAWAH & $\mathrm{Y}=2035+31.97 * \mathrm{TME}$ & 0.63 & 2930 & 40.76 & 180.55 & -5.15 & 2.21 \\
\hline 4 & ETHA & $\begin{array}{l}\mathrm{Y}=2348 \\
+27.03 * \mathrm{TIME}+30.09 * \mathrm{Z} 41\end{array}$ & 0.67 & 2431 & 20.42 & 153.07 & 18.40 & 21.93 \\
\hline 5 & FARRUKHABAD & $\mathrm{Y}=1887+24.28 *$ TIME & 0.73 & 2519 & 56.31 & 90.67 & 7.24 & 8.69 \\
\hline 6 & HARDOI & $\mathrm{Y}=-1237+2.3 * \mathrm{Z} 121$ & 0.45 & 1659 & 17.78 & 184.73 & 11.02 & 21.78 \\
\hline 7 & KANNAUJ & $Y=-2102+3.90 * Z 121$ & 0.52 & 1941 & 24.91 & 185.20 & 10.70 & 19.80 \\
\hline 8 & KANPUR DEHAT & $\mathrm{Y}=17.98+32.20 *$ TIME & 0.57 & 2700 & 29.82 & 212.63 & 5.72 & 8.37 \\
\hline 9 & KANPUR & $\mathrm{Y}=1529+25.20 * \mathrm{TIME}+2.37 * \mathrm{Z} 31$ & 0.62 & 2255 & 14.83 & 186.80 & 6.30 & 5.40 \\
\hline 10 & MAINPURI & $\mathrm{Y}=1816+33.32 *$ TIME & 0.64 & 2716 & 38.80 & 181.42 & -1.68 & 2.57 \\
\hline 11 & MATHURA & $\mathrm{Y}=2187+5.82 * \mathrm{Z} 31$ & 0.55 & 2813 & 13.53 & 166.49 & 1.56 & 28.23 \\
\hline 12 & UNNAO & $\mathrm{Y}=4063+0.73 * \mathrm{Z} 141$ & 0.56 & 1979 & 29.70 & 166.54 & -16.70 & -2.70 \\
\hline
\end{tabular}


Table.2 Validation of model for forecast of rice yield under different districts of Central Uttar Pradesh

\begin{tabular}{|c|l|c|c|c|c|c|c|}
\hline SN & District & \multicolumn{3}{|c|}{$\mathbf{2 0 1 6}$} & \multicolumn{3}{|c|}{$\mathbf{2 0 1 7}$} \\
\cline { 2 - 8 } & & Observed & Forecasted & Error\% & Observed & Forecasted & Error\% \\
\hline $\mathbf{1}$ & AGRA & 2542 & 2284 & 10.15 & 2680 & 2424 & 9.54 \\
\hline $\mathbf{2}$ & AURAIYA & 2959 & 3115 & -5.26 & 3085 & 3160 & -2.44 \\
\hline $\mathbf{3}$ & ETAWAH & 2726 & 2866 & -5.15 & 2964 & 2898 & 2.21 \\
\hline $\mathbf{4}$ & ETHA & 2887 & 2355 & 18.40 & 3025 & 2361 & 21.93 \\
\hline $\mathbf{5}$ & FARRUKHABAD & 2663 & 2470 & 7.24 & 2732 & 2495 & 8.69 \\
\hline $\mathbf{6}$ & HARDOI & 2314 & 2059 & 11.02 & 1297 & 1718 & 21.78 \\
\hline $\mathbf{7}$ & KANNAUJ & 2684 & 2396 & 10.70 & 2987 & 2397 & 19.80 \\
\hline $\mathbf{8}$ & KANPUR & 2796 & 2636 & 5.72 & 2912 & 2668 & 8.37 \\
\hline $\mathbf{9}$ & DEHAT & & & & & & \\
\hline $\mathbf{1 0}$ & MANPUR & 2493 & 2337 & 6.30 & 2504 & 2369 & 5.40 \\
\hline $\mathbf{1 1}$ & MATHURA & 2606 & 2650 & -1.68 & 2754 & 2683 & 2.57 \\
\hline $\mathbf{1 2}$ & UNNAO & 2346 & 2309 & 1.56 & 2451 & 1759 & 28.23 \\
\hline & & 1858 & 2169 & -16.70 & 2098 & 2155 & -2.70 \\
\hline
\end{tabular}

Table.3 Yield forecast models of wheat for different districts of Central Uttar Pradesh

\begin{tabular}{|c|c|c|c|c|c|c|c|c|}
\hline \multirow[t]{2}{*}{ S.N. } & \multirow[t]{2}{*}{ District } & \multirow[t]{2}{*}{ Equation } & \multirow[t]{2}{*}{$\mathbf{R}^{2}$} & \multirow{2}{*}{$\begin{array}{l}\text { Forecast } \\
\text { yield } \\
\text { (Kg/ha) }\end{array}$} & \multirow[t]{2}{*}{$\mathbf{F}$} & \multirow{2}{*}{$\begin{array}{c}\text { Std } \\
\text { Error }\end{array}$} & \multicolumn{2}{|c|}{ ERROR } \\
\hline & & & & & & & 2016 & 2017 \\
\hline 1. & AGRA & $\mathrm{Y}=2834+0.38 * \mathrm{Z} 241+0.5 * \mathrm{Z} 351$ & 0.52 & 3034 & 11.42 & 161.6 & 22.39 & 8.06 \\
\hline 2. & AURIYA & $\mathrm{Y}=3113+0.83 * \mathrm{Z} 131$ & 0.49 & 3105 & 21.33 & 184 & 22.31 & 12.08 \\
\hline 3. & ETAWAH & $Y=3136+17.26 * Z 51$ & 0.52 & 2991 & 23.62 & 171 & 25.93 & 19.22 \\
\hline 4. & ETHA & $\mathrm{Y}=2067+33154 * \mathrm{TIME}+8.50 * \mathrm{Z} 51$ & 0.74 & 2901 & 30.16 & 164 & 12.56 & 5.59 \\
\hline 5. & FARRUKHABAD & $\mathrm{Y}=2804+37.01 * \mathrm{TIME}$ & 0.54 & 3804 & 26.5 & 243 & 4.87 & - \\
\hline 6. & HARDOI & $\mathrm{Y}=2391+34.43 *$ TIME & 0.68 & 3321 & 47.63 & 169 & 10.55 & -0.39 \\
\hline 7. & KANNAUJ & $\mathrm{Y}=2835+36.58 *$ TIME & 0.59 & 3833 & 32.23 & 201.8 & 4.47 & 0.31 \\
\hline 8. & $\begin{array}{l}\text { KANPUR } \\
\text { DEHAT }\end{array}$ & $Y=1528+0.44 * Z 141$ & 0.53 & 3461 & 24.71 & 252 & 26.79 & 15.09 \\
\hline 9. & KANPUR & $Y=1479+0.54 * Z 241$ & 0.60 & 2549 & 31.79 & 184 & 35.10 & 29.67 \\
\hline 10. & MAINPURI & $\mathrm{Y}=2665+35.62 *$ TIME & 0.71 & 3627 & 54.51 & 163 & 11.43 & 3.32 \\
\hline 11. & MATHURA & $\mathrm{Y}=1755+1.55 * \mathrm{Z} 121+18.46 * \mathrm{TIME}$ & 0.68 & 3565 & 21.79 & 153 & 15.54 & 4.78 \\
\hline 12. & UNNAO & $\mathrm{Y}=2001+37.42 *$ TIME & 0.62 & 3012 & 35.44 & 209 & 7.96 & 7.54 \\
\hline
\end{tabular}


Table.4 Validation of model for forecast of wheat yield for different districts of Central Uttar Pradesh

\begin{tabular}{|c|l|c|c|c|c|c|c|}
\hline SN & District & \multicolumn{3}{|c|}{$\mathbf{2 0 1 6}$} & \multicolumn{3}{c|}{$\mathbf{2 0 1 7}$} \\
\cline { 3 - 8 } & & Observed & Forecasted & Error\% & Observed & Forecasted & Error\% \\
\hline 1. & AGRA & 4080 & 3167 & 22.39 & 3528 & 3244 & 8.06 \\
\hline 2. & AURIYA & 4017 & 3121 & 22.31 & 3511 & 3087 & 12.08 \\
\hline 3. & ETAWAH & 4140 & 3067 & 25.93 & 3598 & 2906 & 19.22 \\
\hline 4. & ETHA & 3881 & 3394 & 12.56 & 3374 & 3185 & 5.59 \\
\hline 5. & FARRUKHABAD & 3921 & 3730 & 4.87 & 3421 & 3767 & -10.11 \\
\hline 6. & HARDOI & 3636 & 3252 & 10.6 & 3274 & 3287 & -0.4 \\
\hline 7. & KANNAUJ & 3925 & 3750 & 4.47 & 3798 & 3786 & 0.31 \\
\hline 8. & KANPUR DEHAT & 4588 & 3359 & 26.79 & 3985 & 3384 & 15.09 \\
\hline 9. & KANPUR & 4065 & 2638 & 35.1 & 3714 & 2612 & 29.67 \\
\hline 10. & MAINPURI & 4015 & 3556 & 11.43 & 3715 & 3292 & 3.32 \\
\hline 11. & MATHURA & 4104 & 3466 & 15.54 & 3687 & 3511 & 4.78 \\
\hline 12. & UNNAO & 3191 & 2937 & 7.96 & 3217 & 2975 & 7.54 \\
\hline
\end{tabular}

\section{Wheat yield forecast}

The yield variations explained by model for wheat crop together with standard error are shown in Table 3. Coefficient of determination $\left(\mathrm{R}^{2}\right)$ has been significant at $5 \%$ probability level for wheat in all the twelve districts of central Uttar Pradesh. The $\left(\mathrm{R}^{2}\right)$ was ranged between 49 (Auriya) and $74 \%$ (Etawah). The percent $\mathrm{F}$ value was ranged between 11.42 (Agra) and 54.51 (Mainpuri), However, the percent standard error was ranged between 133.0 (Hathrus) and 252.0 (Kanpur dehat). The best agrometeorological indices to incorporate in the agrometeorological yield forecast model was selected as Tmin x RH-I (Z241), Rain x RH-II (Z351) for Agra, district, Tmax. x Rain (Z131) for Auriya district, RH-II (Z51) for the Etawah, Time, RH-II (Z51) for Etah district, TIME for Farrukhabad, Firozabad, Hardoi, Kannauj, Mainpuri and Unnao district, Tmin x RH-I (Z241), Tmin. x RH-II (Z251) for Hathrus, Tmax. x RH-I (Z141) for Kanpur dehat, Tmin. x RH-II (Z241) for Kanpur and Tmax x Tmin (Z121), TIME for Mathura district.

The validation of model for wheat during the year 2016-17 and 2017-18 has been shown in
Table 4. Results revealed that the models estimated error in Agra (22.39\%), Auriya (22.31\%), Etawah (25.93\%), Etah (12.56\%), Farrukhabad (4.87\%), Hardoi (10.55\%), Kannauj (4.47\%), Kanpur Dehat (26.79\%), Kanpur (35.10\%), Mainpuri (11.43\%), Mathura $(15.54 \%)$ and while over estimation was observed for Kannauj (4.47\%), Farrukhabad (4.87\%) and Unnao (7.96\%) in 2016-17. During 2017-18 models underestimated in Auriya (12.08\%), Etawah (19.22\%), Farrukhabad ($10.10 \%)$, Hardoi (-0.39\%), Kanpur Dehat (15.09\%), Kanpur (29.67\%) and over estimated in Agra (8.06\%), Etah (5.59\%), Kannauj (0.31\%), Mainpuri (3.39\%), Mathura (4.75\%) and Unnao (7.54\%) districts. Results also indicated that the model has predicted that the wheat yield with in $\pm 10 \%$ error in all the twelve districts of Central Uttar Pradesh. Maximum \& minimum temperatures, RH-I and RH-II are important agrometeorological indices for wheat yield forecast. Predicted yield was closed to observed yield, therefore, it can be used for yield forecasting and planning purpose.

The results showed that agro-meteorological yield model explained the yield variability due to variations in minimum, maximum 
temperatures together with relative humidity with respect to major wheat growing districts of Agra, Etha, Kannauj, Mainpuri, Mathura and Unnao. Whereas, variations in rain also influenced in other districts where heat cultivation is comparatively less intensive. According to Singh et al, (2010) and Singh et al., (2011). Over the past few years, the per hectare yield of wheat in India has fallen due to the temperature rising steadily in January, February and March (a period most crucial for the wheat crop). Maximum and minimum temperatures are very sensitive weather parameters for wheat crop, arise by $0.5^{\circ} \mathrm{C}$ in winter temperature is projected to reduce wheat yield by 0.45 t ha-1 in India (Lal et al., 1998). Wheat growing belts of this region are also largely influenced by maximum and minimum temperature prevailed during the cropping season. Therefore, it can be infer that maximum and minimum temperatures together with $\mathrm{RH}$ found were significant weather parameters for deciding wheat productivity in the region.

In conclusion, yield forecast has been done for $r$ ice and wheat crops for twelve districts of Central Uttar Pradesh. The developed models have reasonably good $\mathrm{R}^{2}$ between 45 to $73 \%$ variation in rice crop yield and between 49 to $74 \%$ variation in wheat crop yield in different districts. The F value between 13.53 to $57.20 \%$ variation for rice crop and between 11.42 to $54.51 \%$ variation for wheat crop in different districts. The percent standard error was between 90.67 to $217.73 \%$ for rice crop and between 153 to $252 \%$ for wheat crop. The models were validated with $\pm 10 \%$ error in all the twelve districts of Central Uttar Pradesh. Therefore, it could be used for yield forecasting satisfactorily for both crops and for all the twelve districts of central plan zone of Uttar Pradesh. Further, by and large, the maximum and minimum temperatures in combination with relative humidity have formed most important agrometerological indices which can useful in forecasting of yield of rice and wheat crop in the region.

\section{References}

Agrawal, R and Mehta, S.C. (2007). Weather based forecasting of crop yields, pests and diseases-IASRI models. J.Ind.Soc.Agril.Statist., 61(2): 255-263.

Anonymous, (2010). Directorate of Economics and Statistics, Department of Agriculture and cooperation, India.

Ghosh, K., Balasubramanian, R., Bandopadhyay, S., Chattopadhyay, N., Singh, K.K. and Rathore, L. S. (2014). Development of crop yield forecast models under FASAL - a case study of kharif rice in west Bengal. $\mathrm{J}$. Agrometerology, 16 (1): 1-8.

Lal, M., Singh, K.K., Rathore, L.S., Srinivasan, G. and Saseendran, S.A. (1998). Vulnerability of rice and wheat yields in NW india to future changes in climate. Agric. For, Meterol., 89:101-114.

Singh, H., Singh, K.N., Hasan, B. and Khan, A.A. (2010). Agro climate models for prediction of growth and yield of rice (Oryza sativa) under temperate Kashmir conditions. Indian J. Agric. Sci., 80(3): 254-257.

Singh, K., Sharma, S.N. and Sharma, Y., (2011). Effect of high temperature on yield attributing traits in Bread Wheat. Bangladesh J. Agric. Res., 36(3): 415426.

\section{How to cite this article:}

Naushad Khan, Ajay Kumar, Vijay Dubey, C.B. Singh, Sanjeev Kumar and Shubham Singh. 2020. Estimated Yield Forecasting of Rice and Wheat for Central Uttar Pradesh using Statistical Modal. Int.J.Curr.Microbiol.App.Sci. 9(08): 2490-2495. doi: https://doi.org/10.20546/ijcmas.2020.908.284 